\title{
Coronavirus pandemic and the Slovak medical faculties
}

\author{
Demes $\mathrm{P}^{1}$, Traubner $\mathrm{P}^{2}$ \\ Ist Department of Neurology, Faculty of Medicine, Comenius University in Bratislava, \\ Bratislava, Slovakia. paveltra@hotmail.com
}

\begin{abstract}
The Covid-19 pandemic has fully opened the debate on the complexity of the problem, which goes far beyond medical and epidemiological analyzes and proposals, although these are key to the decisions of leaders in the decisive sphere. Critical situations always force us to look for new methods. This is also indicated by paradigmatic changes in the overall functioning and position of medical faculties in Slovakia and abroad $(1,2,3)$. The adaptation of the faculty administration at the time of this crisis is admirable in many respects and essential for the long-term societal struggle with the pandemic. (Ref. 3). Text in PDF www.elis.sk KEY WORDS: COVID-19, Coronavirus 2019, pandemic, public health, medical faculties in Slovakia.
\end{abstract}

Beginning in March, all medical faculties in Slovakia closed their laboratories and classes for all students and the teachers went online to communicate with medical students and future health employees. Many teachers and students got fully engaged in the fight against the epidemic. This article seeks to bring information on fast adjustment of three medical faculties, namely the Medical Faculty of Comenius University in Bratislava, the Jessenius Medical Faculty of Comenius University [UK] in Martin, the Medical Faculty of the University of Pavol Jozef Safarik in Kosice and the Slovak Health University (SZU) in Bratislava at this current critical and unprecedented time.

The operation of the Slovak medical faculties at the time of the Coronavirus pandemic

The Medical Faculty of the Comenius University in Bratislava, Dean Juraj Steno

LF UK in Bratislava was the first to stop contact classes on March 5, 2020. The decision was taken by the faculty management afterit heard about a possible coronavirus infection of a foreign student, which, however, was not confirmed by the laboratory. Subsequently, the UK Crisis management staff terminated regular contact classes at the whole university and the crisis management staff of the Slovak Republic adopted a decision on terminating classes in all schools and school facilities as of March 16, 2020 across the country.

Both students and their teachers shortly changed from contact classes to a remote method of learning, i.e. communication and

${ }^{1}$ Free Analyst, Bratislava, and ${ }^{2}$ Ist Department of Neurology, Faculty of Medicine, Comenius University in Bratislava, Bratislava, Slovakia.

Address for correspondence: P. Traubner, Prof, MD, DSc, Ist Department of Neurology, Faculty of Medicine, Comenius University in Bratislava, Bratislava, Slovakia. classes were transferred to electronic teaching through emails or computer systems as Microsoft Teams, Moodle or Skype (commented lectures and practical seminars, online testing or interactive seminars with smaller groups of students), both in the Slovak and English languages. The institutes and clinics of the Medical Faculty of ComeniusUniversity have published their presentations of lectures and seminars on MEFANET or on the websites of the workplaces. Most offices of LF UK presented its lectures and seminars on their faculty websites. $\mathrm{PhD}$ programs went online, too.

At the present time, the faculty began to adjust its contact teaching activities to the online system also during the upcoming examinations time. Thus, experts began to analyze options of online testing of students, and if necessary, to provide online state examinations by means of video discussions that would be made by both professors and students on computers from their homes. The faculty prepared technical procedures for online examination of students and on April 6, it was the first in Slovakia to start conducting state exams using the distance method using video calls via MS Teams.

As a matter of fact, they want the 6th year students to allow to finish their studies in the regular time and thus to enable them to fully engage in providing health care that is of utmost importance at this point.

There are some offices of LF UK that have remained in full operation until now. They include clinical workplaces, but also the Institute of Microbiology of LF UK and the National University Hospital of Bratislava [UNB]. The employees of the institutes, who are engaging in scientific and educational activities, moved to the home office. The Dean's offices have continued their regular work.A number of standard academic activities have been cancelled until further notice; this concerns also sessions of the Academic Board, Academic Senate, or the Dean's college. The regular sessions of the LF UK management have been held online. 
481-483

\section{The Medical Faculty of the University of Pavol Jozef Safarik in Kosice (UPJS LF), DeanDaniel Pella}

Regular teaching and classes in university facilities were stopped, but they have been replaced by remote teaching. Staff is regularly responding to all requests from other workplaces and students that concern information for students on the changes in classes and curriculum on UPJS LF websites; publishing electronic supporting materials for lectures on the UPJS LF portal; activation of university email boxes of the university staff and students; activation of accounts on the UPJS LF portal; consultations concerning the academic information system AiS2 works (communication with students, links) and on the UPJŠ LF portal; consulting and support on electronic testing options (MS Forms, Rogo, Moodle UPJŠ) as well as consulting and support of online lectures (MS Teams, Skype, and eZuce Vibe).

\section{Jessenius Medical Faculty of the Comenius University in Martin (JLF UK), Dean Andrea Calkovska}

Similar to other faculties, ILF UK continues in educating its students by distance learning.Educator, with the support of employees of the Institute of Information Technologies, the Academic Library, and the audiovisual center and Simulation Education Center provide online lectures, seminars, and practical exercises. Virtual patient access is available. For this purpose, the faculty has arranged a portal to support distance learning. https://www. jfmed.uniba.sk/distancne-vzdelavanie. Students acquire clinical and practical skills in the framework of volunteer activities in the field (triage tents, medical facilities, DDS, infolines, etc.). Employees of clinics in the Martin University Hospital in a relatively unchanged mode. Other pedagogical and scientific researchers work mostly from home, preparing materials for education, paying attention to manuscripts of scientific or professional publications. Operation of other workplaces and papers is carried out in such a manner that all necessary activities at the faculty are adequately ensured. The educational process is carried out on the basis of a new timetable of the summer semester, which is in accordance with the Methodical Guidelines for the Organization of Studies at Comenius University in Bratislava. Currently, the first ever state examinations take place online at the faculty, allowing students of the last years to complete their studies in due time. The faculty thus responds to the need for the whole society and the interest of the Ministry of Health to increase the number of healthcare workers during the time of the pandemic caused by the Novel Coronavirus.

\section{The Slovak Medical University (SZU), Rector Peter Simko}

SZU includes, apart from the Medical Faculty, a Faculty of Nursing and Health Professional Studies, Faculty of Public Health and Faculty of Health located in Banská Bystrica. Online study with necessary study materials have been provided at SZU. Final works, reviews, communication among faculties, teachers and opponents is made possible by means of a modular academic information system of MAIS.

\section{Activities of faculty staff and students in order to reduce the Coronavirus crisis}

LF UK in Bratislava. Both regular students and PhD students have been engaged in a number of volunteer activities. More than 150 students have been involved in the call centers within the National Center of Health Information (NZCI) and also the Regional Office of the Public Health (RUVZ). Over 50 medical students have taken part in trainings and gradually are joining the central admission centers in hospitals, or they provide assistance in examining patients and collection of materials for microbiological tests of a great number of patients at the Clinic of Infectology and geographic medicine of LF UK and UNB where all patients suspected of COVID-19 infection arrive. They also try to solve any issues connected with providing personal protection equipment (PPE).

LF UK employees, who also work in teaching hospitals too, provide their services beyond their regular duties in hospitals, particularly in UNB, while many of them participate in trainings and courses aimed at managing an overwhelming number of patients infected by coronavirus. The staff of the Institute of Microbiology of LF UK and UNB cooperate with more than 30 volunteers from among employees of theoretical institutes of LF UK, who have not been involved in providing health care yet and who showed willingness to assist in laboratory diagnostics of the coronavirus infection. LF UK along with the Scientific Park of the Comenius University in Bratislava includes highly qualified personnel and space options.

Assistant Professor of the Institute for Simulation and Virtual Medical Education of LF UK Dr. Andrej Turzo participated in launching a mobile application Stay Healthy (www.zostanzdravy. sk) that can help to fight coronavirus infection. Several specialists, like Dr. Vladimir Krcmery, who is also a member of the Central Crisis Staff of the Slovak Republic, then Drs. Peter Sabaka, Alexandra Brazinova, and others, have been engaging in keeping the broad public informed and calm.

UPJS LF in Kosice and its Institute of Epidemiology from the outset started to conduct laboratory diagnostics of COVID-19 at the Department of Medical Microbiology of RÚVZ and they offered their own equipment necessary for the molecular virus detection. The Institute of Medical Microbiology and Immunology of UPJS and of the University Hospital of Louis Pasteur (UNLP) in Kosice has also provided testing for the presence of coronavirus (standard and fast tests).

UVP Medipark, the medical university scientific park in Košice lent 6 equipments for artificial lung ventillation to the Clinic of Pneumology and Ftiseology of UNLP, which were purchased from EU Structural funds. The Slovak Ministry of Education exempted, for the time of pandemic,all equipment, which was originally designated for scientific and research purposes, to be used for prevention of infection or for the treatment of infected patients.

The UPJS LF students vigorously joined in voluntary activities; at the present time, 127 volunteers have enrolled. These numbers grew also thanks to an excellent management through emails and telephone calls; mobilization of both the Association of Medical 
Students and the Association of Dental Students under coordination of the chairman of the student section of the Academic Senate of UPJS LF. Students have assisted at several levels of the Kosice and Presov regional local administration in treating patients as nurses or in call centers.

JLF UK in Martin offered its capabilities to test the coronavirus infection to the Slovak Ministry of Health (MZ SR). Activities of clinical staff in hospital have been determined by their job description and its location. Dr. Henrieta Hudeckova, who is the chief expert of the Slovak Ministry of Health and the head manager of the Institute of Public Health of JLF UK in Martin, has played a significant role in current situation.

A group of volunteers was created out of employees with medical education, who did not involve clinical practice and of employees without medical practice. These people are available, if needed, to UNM. Noteworthy are also the volunteer activities of general medicine, dentistry, and of non-medical study programs - the number of volunteers has reached approx. 180 here. Martin Tkac, a 4th year student has coordinated activities of students, who are enrolled in regular university studies abroad. They joined call centers of NCZI, UNM, etc.

SZU in Bratislava has been practically from the outset of the hospitalization of COVID-19 patients cooperating closely with the UNB infection facility in Ladislav Derer hospital of UNB in Bratislava Kramare. A Crisis Management Staff has been established in SZU. Dr. Katarina Holeckova, employed in LF SZU, is the head of collection team in the infection facility and she is assisted from the beginning by students, especially at the first contact places with patients (triage). SZU provides lists of students - volunteers, who cowork with the National Institute of Cardiovascular
Diseases (NÚSCH). The Faculty of Public Health and the Faculty of Nursing and Specialized Studies of SZU offer skills for filtering of Master's students for the medical facilities, as well as Bachelor's degree students to help with baby-sitting of employees children.

SZU also provides a highly appreciated quarantine accomodation for rescuers' teams, for nurses and X-ray workers, who have participated in the collection of samples at the Kramare Hospital on a daily basis. They get a chance to take a rest after highly demanding shifts without being forced to commute to their suburban homes in the vicinity of Bratislava. SZU offered its parking lot for medical staff of Kramáre hospital at the time of increased mobility of patientsat the filtering. The Faculty of Health of SZU coordinated the establishment of the Information line concerning the COVID-19 disease at the Faculty hospital with polyclinic of F.D. Roosevelt in Banská Bystrica. Clinical and scientific workers of SZU, in cooperation with the Slovak Academy of Sciences (SAV) cooperated and on April 9, 2020 submitted to the Slovak Ministry of Health current material COVID-19-Clinical Aspects and Risk Factors. Its preparation was done by I. Solovic, I. Simkova, K. Raslova,A. Penesova,S. Pastorekova, I. Lazurova,B. Klempa,R. Imrich, andJ. Pastorek.

\section{References}

1. Sahu P. Closure of Universities Due to Coronavirus Disease 2019 (COVID-19) : Impact on Education and Mental Health of Students and Academic Staff. Cureus 2020; 12(4).

2. Wang Ch et al. Risk Management of Covid-19 by Universities in China. J Risk Financial Manag 2020;13: 36.

3. Combs et al. First Statement on Preparation for the COVID-19 Pandemic in Large German Speaking University-based Radiation Oncology Departments. Radiation Oncol 2020; 15:74. 